\title{
Особенности концентрирования полярных биологически активных соединений на сверхсшитом полистироле
}

\author{
С. Г.Дмитриенко ${ }^{1}$, Д.Х.Н., В. В. Апяри ${ }^{1}$, Д.Х.Н.,В.В.Толмачева ${ }^{1,2}$, К.Х.Н. \\ ${ }^{1}$ Московский государственный университет имени М. В. Ломоносова, Москва \\ ${ }^{2}$ Институт общей и неорганической химии им. Н. С. Курнакова РАН, Москва \\ apyari@mail.ru
}

\begin{abstract}
Систематизированы сведения об особенностях концентрирования полярных биологически активных соединений на сверхсшитом полистироле (ССПС) - коммерчески доступном микропористом полимерном сорбенте - в целях химического анализа. Даны общие характеристики сверхсшитых полистиролов. Приведены примеры сорбции на сорбентах этого типа соединений разных классов - метилксантинов, сульфаниламидов, тетрациклинов, флавоноидов и др. Обсуждены различные приемы аналитического концентрирования с применением ССПС и сочетания концентрирования с методами последующего определения. Показаны возможности группового концентрирования органических соединений на ССПС, а также прямого (без пробоподготовки) извлечения целевых аналитов из анализируемых объектов.
\end{abstract}

\section{ВВЕДЕНИЕ}

Концентрирование полярных биологически активных соединений для последующего определения их малых содержаний в различных объектах представляет собой актуальную задачу современной аналитической химии. Одним из наиболее перспективных методов считается сорбционное концентрирование. Хорошо известно, что на эффективность и селективность сорбционного концентрирования влияют природа сорбента, условия концентрирования и вариант реализации процедуры. Прежде всего, важен первый фактор, поэтому по сей день актуален поиск и разработка сорбентов для решения разнообразных практических задач химического анализа.

Среди огромного числа известных полимерных сорбентов особое место занимает сверхсшитый полистирол (ССПС). Этот сорбент синтезировли сотрудники института элементоорганических соединений РАН В.А. Даванков и М. П. Цюрупа [1, 2]. Начиная с конца 1990-х - начала 2000-х годов он активно внедряется в аналитическую химию, в основном благодаря работам, выполненным в группе В.А. Даванкова [3, 4], и на кафедре аналитической химии МгУ имени М.В.Ломоносова [5-10]. На сегодняшний день сверхсшитые сорбенты широко известны под различными торговыми марками и отличаются пористостью, емкостью и сорбционными свойствами. Например: Macronet MN, Purosep, Chromalite (Purolite International, Великобритания), Isolute ENV+ (International Sorbent Technology, Великобритания), LiChrolut EN (Merck Millipore Corporation, Германия), HySphere (Spark Holland, Голландия), HR-P (Macherey Nagel, Германия), Диапак П-3 (Биохиммак СТ, Россия) [10, 11].

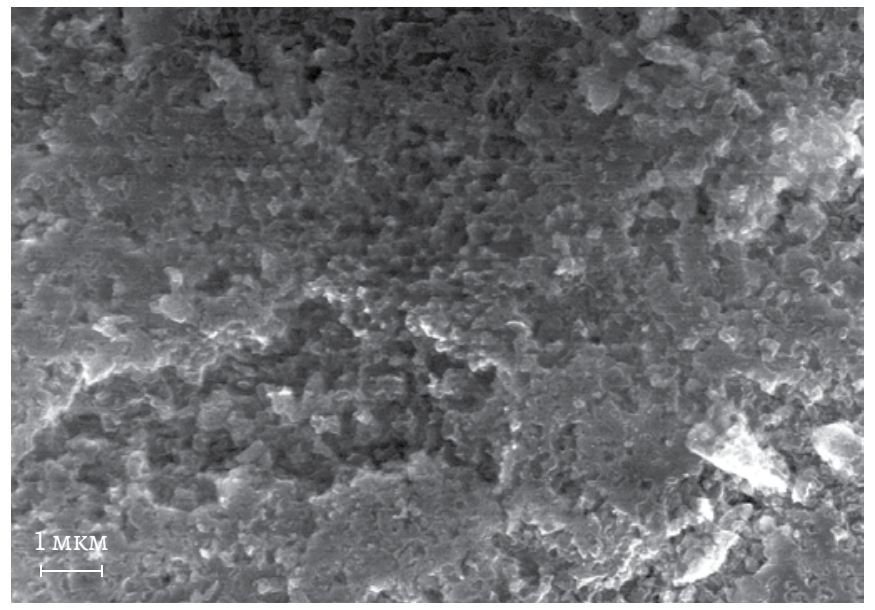

Puc. 1. Пример электронной микрофотографии поверхности ССПС 
В статье систематизированы сведения об особенностях применения ССПС для концентрирования полярных биологически активных соединений.

\section{ОСОБЕННОСТИ СВЕРХСШИТОГО ПОЛИСТИРОЛА КАК СОРБЕНТА}

Сверхсшитый полистирол получают путем сшивания макромолекул полистирола или его сополимера с дивинилбензолом различными способами, например в присутствии кислот Льюиса. В результате формируется жесткая микропористая структура с большой площадью удельной поверхности (более 1000 м²/г), из которой примерно половина приходится на микропоры, то есть поры с размерами меньше 2 нм (рис. 1) [11]. Эти структурные и химические особенности сверхсшитого полистирола в значительной степени определяют его уникальные сорбционные свойства [12]. Так, высокоразвитая поверхность определяет высокую сорбционную емкость, а большая доля микропор - избирательность в отношении маленьких молекул, что позволяет считать сверхсшитый полистирол материалом ограниченного доступа. В то же время химические особенности полимера допускают возможность гидрофобных, п-п- и катион-пвзаимодействий. Кроме того, даже немодифицированный сверхсшитый полистирол может вступать в полярные взаимодействия и проявлять ионообменные свойства благодаря поверхностным полярным группам и льюисовым центрам остатков катализатора. Все это приводит к эффективной сорбции соединений различной природы и полярности (табл. 1). Обращает на себя внимание многообразие сорбируемых соединений, и, несмотря на гидрофильность многих, их коэффициенты распределения зачастую достигают $10^{4} \mathrm{~cm}^{3} / г$.

При сравнении эффективности концентрирования полярных биологически активных веществ на ССПС с другими широко распространенными сорбентами можно прийти к выводу, что он в ряде случаев выгодно отличается. Так, если степени извлечения таких лекарственных препаратов, как пропранолол, S- и R-пропранолол глюкуронид, 4-оксипропранолол сульфат и нафтизин, на гидрофобизированном силикагеле RP-18 в зависимости от природы вещества варьируются от 29 до 94\%, то на ССПС они примерно одинаковы и составляют от 89 до 99\% [32]. По сравнению с другими полимерными сорбентами, такими как Strata-X, Strata SDB-L и диэтиламиноэтилцеллюлоза, ССПС также выглядит весьма выигрышно, что показано, в частности, на примере извлечения антибиотиков тетрациклинового ряда [13]. Из представленных на рис. 2 данных видно, что коэффициенты распределения, достигаемые на ССПС, иногда существенно выше, чем на перечисленных выше полимерных сорбентах.
Таблица 1. Примеры киассов сорбируемых на ССПС полярных органических соединений и достигаемые при этом коэффициенты распределения (D)

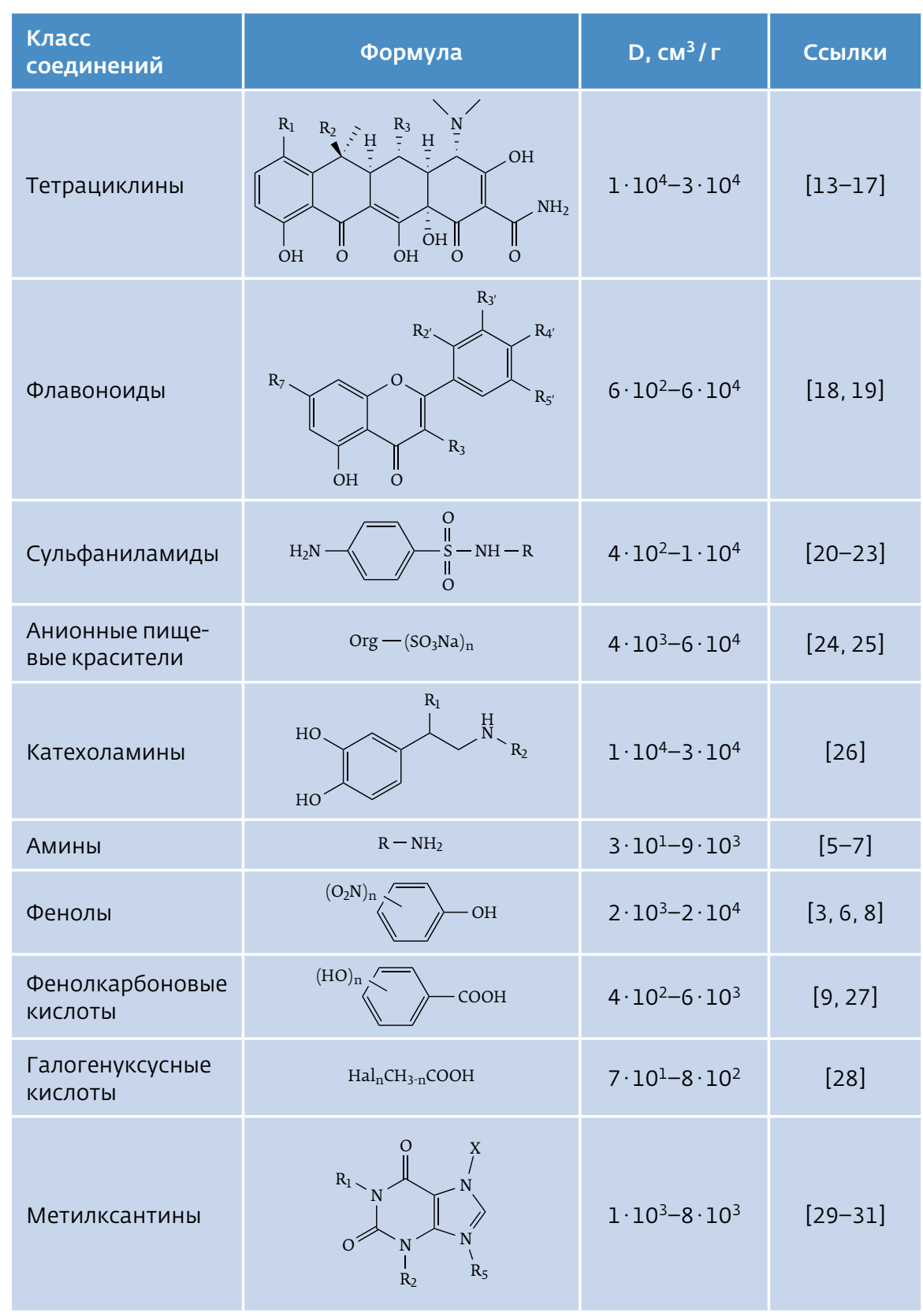




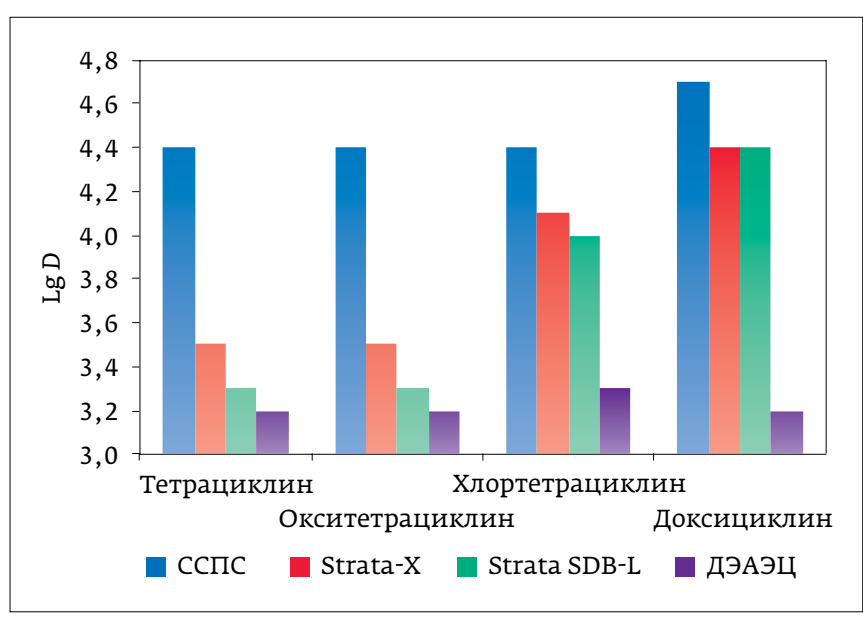

Puc. 2. Сравнение логарифмов коэффициентов распределения антибиотиков тетрацикиинового ряда на ССПС и других полимерных сорбентах

Хорошие сорбционные характеристики ССПС позволяют эффективно извлекать полярные органические соединения не только из водных, но и водно-органических сред. Это важно, когда в ходе пробоподготовки для извлечения аналитов из твердых образцов используют органические растворители. Так, антибиотик тетрациклинового ряда окситетрациклин количественно сорбируется на ССПС из сред, содержащих до 10\% ацетонитрила и этанола и до 30\% метанола. Другие, более гидрофобные, представители ряда тетрациклинов количественно извлекаются из сред с еще большим содержанием метанола [14].

Количественное извлечение полярных биологически активных соединений, как правило, достигается в широком диапазоне $\mathrm{pH}$ пробы вплоть до шести единиц, что свидетельствует о высокой эффективности сорбционного концентрирования на ССПС, вероятно, связанной с реализацией разных типов взаимодействий с сорбатом. Интересно отметить, что хотя среди основных типов межмолекулярных взаимодействий, характерных для ССПС, выделяют гидрофобные, п-п-, и катион-п-взаимодействия, показано, что поверхность ССПС может быть отрицательно или положительно заряженной в зависимости от рН (рис. 3) [33]. Следовательно, существуют области рН, где ССПС проявляет анионоообменные или катионообменные свойства. Этот факт открывает возможность применения дополнительных механизмов удерживания веществ. Отмеченную особенность сорбента в сочетании с кислотно-основными свойствами, характерными для конкретного класса аналитов, можно использовать для управления селективностью извлечения. Так, например, при рН 10 тетрациклины сорбируются на сСпС количественно [15], в то время как степень извлечения сульфаниламидов падает практически до нуля [22].

Коэффициенты распределения полярных биологически активных соединений на ССПС, как правило, коррели- руют с их гидрофобностью. Например, для фенолов они возрастают по мере уменьшения растворимости соединений в воде и увеличения их коэффициентов распределения в системе октанол-вода (параметров гидрофобности) в ряду: фенол <n-крезол<n-нитрофенол <2,4-динитрофенол< <-нитрофенол<2,4-дихлорфенол и в ряду: гидрохинон < резорцин <пирокатехин [6, 34]; для метилксантинов, сульфаниламидов и тетрациклинов - в рядах: дипрофиллин < теобромин < теофиллин < кофеин < пентоксифиллин [35]; сульфаниламид < сульфаметоксипиридазин <сульфаметазин < сульфаметоксазол < сульфахлорпиридазин [22, 23]; тетрациклин< окситетрациклин<хлортетрациклин<доксициклин $[14,15]$, соответственно.

\section{СОРБЦИОННОЕ КОНЦЕНТРИРОВАНИЕ НА СВЕРХСШИТОМ ПОЛИСТИРОЛЕ}

Из литературы известны два классических варианта реализации процедуры сорбционного концентрирования на ССПС - статический и динамический, а также предложенный относительно недавно способ магнитной твердофазной экстракции.

Независимо от используемого варианта, прежде всего, важна предварительная активация ССПС смешивающимся с водой растворителем, например ацетонитрилом или метанолом, поскольку она обеспечивает последующий контакт микропористой структуры полимера с водным раствором.

Достоинством ССПС для статического варианта концентрирования (дисперсионной твердофазной экстракции), состоит в том, что сорбент легко отделяется от раствора путем седиментации без последующего фильтрования. При этом требуемая для количественного извлечения навеска

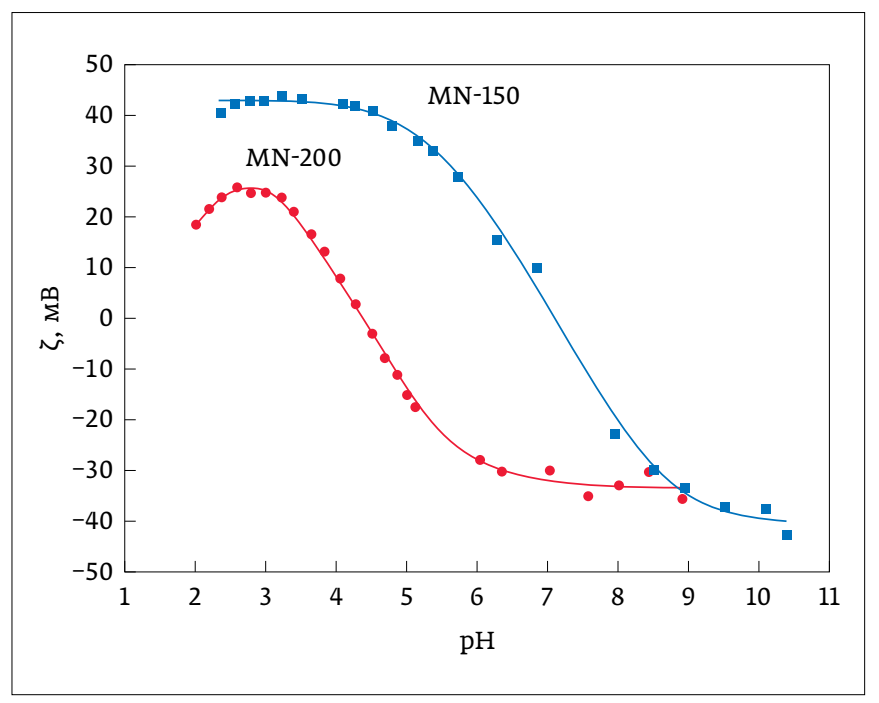

Puc. 3. Дзета-потенциал ССПС разных марок при различном рH. Воспроизведено с разрешения Royal Society of Chemistry, полученного через Copyright Clearance Center, из [33] 
Табпица 2. Степени извлечения флавоноидов и метилксантинов на CCПС (R,\%) в статическом и динамическом вариантах сорбционного концентрирования

\begin{tabular}{|l|c|c|}
\hline \multirow{2}{*}{ Флавоноиды } & \multicolumn{2}{|c|}{$\mathbf{R} \%$} \\
\cline { 2 - 3 } & $\begin{array}{c}\text { Динамический } \\
\text { вариант }\end{array}$ & $\begin{array}{c}\text { Статический } \\
\text { вариант }\end{array}$ \\
\hline Нарингенин & $99 \pm 2$ & $98 \pm 4$ \\
\hline Хризин & $99 \pm 2$ & $97 \pm 2$ \\
\hline Нарингин & $95 \pm 3$ & $51 \pm 2$ \\
\hline Кверцетин & $98 \pm 2$ & $95 \pm 5$ \\
\hline Рутин & $90 \pm 4$ & $33 \pm 2$ \\
\hline Морин & $98 \pm 4$ & $80 \pm 2$ \\
\hline
\end{tabular}

\begin{tabular}{|l|c|c|}
\hline \multirow{2}{*}{ Метилксантины } & \multicolumn{2}{|c|}{$\mathbf{R , \%}$} \\
\cline { 2 - 3 } & $\begin{array}{c}\text { Динамический } \\
\text { вариант }\end{array}$ & $\begin{array}{c}\text { Статический } \\
\text { вариант }\end{array}$ \\
\hline Пентоксифиллин & $100 \pm 1$ & $97 \pm 2$ \\
\hline Кофеин & $100 \pm 1$ & $94 \pm 3$ \\
\hline Теофиллин & $100 \pm 1$ & $91 \pm 3$ \\
\hline Теобромин & $100 \pm 1$ & $84 \pm 2$ \\
\hline Дипрофиллин & $100 \pm 1$ & $84 \pm 3$ \\
\hline
\end{tabular}

сорбента часто составляет всего несколько десятков миллиграмм, а для элюирования сорбатов достаточно 1-2 мл растворителя. Время достижения сорбционного равновесия не превышает 1-5 мин для аминов, фенолов и цвиттерионных красителей, 20 мин для фенолкарбоновых кислот, сульфаниламидов и тетрациклинов и 30 мин для метилксантинов [10].

В случае динамического сорбционного концентрирования на ССПС, благодаря высокой сорбционной эффективности этого материала, для количественного извлечения аналитов, как правило, достаточно высоты слоя сорбента в картридже всего 1-2 мм. При этом возможно концентрирование из объемов до нескольких литров, что обеспечивает высокие коэффициенты концентрирования аналитов. При прочих равных условиях этот вариант более совершенен, чем статический, с технологической и практической точек зрения. В табл. 2 приведены степени извлечения флавоноидов [18] и метилксантинов $[29,30]$ при динамическом и статическом концентрировании. Видно, что показатели динамического варианта иногда существенно лучше, например, для нарингина, рутина, теобромина и дипрофиллина. При этом после промывки картридж с сорбентом можно использовать многократно. Десорбцию сконцентрированных веществ можно провести как индивидуальными растворителями метанолом, ацетонитрилом, этанолом, - так и с большим эффектом, если взять смеси растворителей с водными растворами реагентов, например кислот, или с другими растворителями. Показано [14], что смесь ацетонитрила с метанолом в объемном соотношении 1:1 оказывается гораздо более эффективным элюентом для антибиотиков тетрациклинового ряда, чем индивидуальные компоненты.

Для реализации магнитной твердофазной экстракции необходим магнитный сорбент, который легко отделяется от раствора под действием постоянного магнитного поля. Описаны три основных способа получения магнитного ССПС введение магнитных наночастиц (например, $\mathrm{Fe}_{3} \mathrm{O}_{4}$ ) при синтезе сорбента, сорбционное модифицирование наночастицами готового сорбента или синтез наночастиц в готовом сорбенте [32, 36-38]. Важная особенность композитов ССПС с суперпарамагнитными наночастицами состоит в том, что кривая намагниченности этих материалов проходит через ноль, поэтому при отключении магнитного поля сорбент полностью размагничивается и может быть легко ресуспендирован. В результате сконцентрированные аналиты быстро элюируют, и композит можно использовать повторно. Как правило, концентрирование методом магнитной твердофазной экстракции включает сорбцию при перемешивании в статическом режиме, отделение сорбента при помощи магнита и декантацию раствора, элюирование сконцентрированных веществ путем ресуспендирования магнитного ССПС в растворителе, повторное отделение сорбента при помощи магнита и анализ полученного концентрата.

\section{СОЧЕТАНИЕ СОРБЦИОННОГО КОНЦЕНТРИРОВАНИЯ НА ССПС С МЕТОДАМИ ПОСЛЕДУЮЩЕГО ОПРЕДЕЛЕНИЯ}

Сорбционное концентрирование на ССПС чаще всего применяют в сочетании с высокоэффективной жидкостной хроматографией (ВЭЖХ). В этом тандеме совмещаются два важных достоинства: высокая сорбционная эффективность и универсальность ССПС и отличная селективность и чувствительность ВЭЖХ-анализа. Сверхсшитый полистирол играет роль сорбента для группового концентрирования веществ, причем как одного, так и нескольких различных классов. Предложены сорбционно-хроматографические способы определения широкого круга полярных биологически активных соединений: фенолов, в том числе нитро- и хлорзамещенных, в водах разного типа с пределами обнаружения $\left(c_{\min }\right)$ вплоть до 3 нг / л $[8,34,39,40]$, метилксантинов в моче $\left(c_{\min }=1-4\right.$ мкг/л) [30], сульфаниламидов $\left(c_{\min }=3\right.$ мкг / л) [22] и тетрациклинов ( $c_{\min }=0,6-2$ мкг/л) [14] в водах. Концентрирование на ССПС снижает пределы обнаружения на 
несколько порядков, делая возможным определение следовых количеств веществ. Сопоставление трех типов коммерчески доступных полимерных сорбентов [41] - PLRP-S, LiChrolut EN и Isolute ENV - в отношении концентрирования ряда алкил-, нитро- ихлорзамещенных фенолов позволяет заключить, что LiChrolut EN и Isolute ENV характеризуются хорошей и примерно одинаковой эффективностью (степени извлечения для них в большинстве случаев составляют 85-100\%). В то же время PLRP-S имеет наименьший суммарный объем пор при довольно большом их диаметре и поэтому несколько уступает двум другим сорбентам со степенью извлечения на уровне 75-95\%. В сочетании с ВЭЖХ с ультрафиолетовым детектором сорбционное концентрирование на этих сорбентах позволяет проводить определение указанных соединений в грунтовых и речных водах с пределами обнаружения на уровне 0,01-0,4 и 0,02-2 мкг / л соответственно.

Помимо ВЭЖХ сорбцию на ССПС можно сочетать с методом газовой хроматографии для определения фенилкарбоновых кислот в модельных растворах, имитирующих сыворотку крови человека [42].

Метод магнитной твердофазной экстракции предложено использовать в сочетании с ВэжХ с массспектрометрическим детектированием для определения ацетаминофена и структурно-родственных биологически активных веществ [43]. Показано, что достигаются степени извлечения не менее $68 \%$ даже для самого гидрофильного представителя выбранного круга аналитов. При этом возможно извлечение целевых веществ из сыворотки крови без удаления матричных компонентов.

В спектрофотометрии ССПС также нашел применение для предварительного концентрирования аналитов методом дисперсионной [21] и магнитной твердофазной экстракции [44]. В указанных работах с помощью ССПС (или магнитного ССПС) концентрировали сульфаниламиды, в результате чего удалось достичь пределов обнаружения 20-30 или 5-10 мкг / л соответственно. Методики применены при анализе проб молока. Примечательно, что не требуется осаждения белков молока, и пробоподготовка сводится всего лишь к разбавлению пробы, поскольку ССПС - микропористый материал ограниченного доступа и не сорбирует крупные молекулы.

Жесткость полимерной сетки и малая набухаемость ССПС могут служить основанием для его использования в качестве неподвижной фазы в хроматографии. Традиционные сорбенты на основе силикагеля имеют пониженную гидролитическую стабильность в водных и водно-органических средах, которая сильно уменьшает время жизни хроматографической колонки вне допустимого интервала рН 2-8, а также лишает возможности кислотной или щелочной промывки загрязненной колонки с целью повторного использования. Сверхсшитый полистирол лишен этого недостатка, его можно использовать в экстремальных по кислотности/щелочности условиях, которые иногда необходимы для прямого хроматографического разделения некоторых антоцианов, алкалоидов, белков и других сильноосновных и сильнокислотных полярных соединений. Например, шесть белков были разделены при рН 12,2 на колонке, заполненной фазой PRP-3 (10 мкм) [12].

Ионообменные свойства ССПС предложено использовать в ионообменной хроматографии [33] для разделения некоторых анионов на колонке, заполненной этим сорбентом. Ряд селективности анионов отличается от типичного и имеет следующий вид: $\mathrm{SO}_{4}^{2-}<\mathrm{Cl}^{-}<\mathrm{IO}_{3}^{-}<\mathrm{Br}^{-}<\mathrm{NO}_{3}^{-}<\mathrm{I}^{-}<\mathrm{SCN}^{-} \sim \mathrm{NO}_{2}^{-} \ll \mathrm{IO}_{4}^{-}$. Основная особенность ССПС здесь - слабое удерживание сульфата и относительно сильное удерживание нитрита, что, вероятно, стало следствием комбинации высокой гидрофобности и анионообменных свойств и интересно с практической точки зрения.

Сверхсшитый полистирол допускает относительно простое модифицирование, поэтому его можно использовать в качестве основы для создания новых сорбентов и реагентов. В частности, такой подход продемонстрирован на примере иммуноферментного анализа [45]. Предложена схема детектирования овальбумина, как модельного белка, основанная на иммуноанализе с электрохимическим детектированием, где используют магнитные микросферы сульфированного ССПС с иммобилизованными антителами. Полученные по модифицированному методу В. А. Даванкова микросферы ССПС сульфировали и осаждали на них наночастицы магнетита, а затем иммобилизовали первичные антитела к овальбумину. Электрохимическое детектирование проводили по току окисления пероксида водорода с использованием антител к овальбумину, меченных пероксидазой хрена. Таким образом, на основе ССПС создан новый иммунореагент.

\section{ВЫвОДЫ}

Сверхсшитые полистирольные материалы - перспективные сорбенты для извлечения и концентрирования полярных биологически активных веществ, главная особенность которых - высокая эффективность и универсальность. Они хорошо сочетаются с такими методами, как высокоэффективная жидкостная хроматография с массспектрометрическим детектированием, для многокомпонентного (multi-residue) анализа. Сорбенты обладают жесткой структурой и высокой устойчивостью, поэтому их можно применять в относительно экстремальных условиях (сильнокислые/сильнощелочные среды, агрессивные растворители, высокие давления). Еще одна важная особенность материалов этого типа - селективность в отношении низкомолекулярных соединений, что в ряде случаев позволяет избежать предварительного удаления высокомолекулярных матричных компонентов и упростить пробоподготовку.

Авторы признательны Российскому научному фонду за финансовую поддержку проведенных исследований (грант № 18-73-10001). 


\section{ЛИТЕРАТУРА}

1. Даванков В. А., Рогожин С. В., Цюрупа М. П. Патент № 299165 СССР, 1969.

2. Даванков В.А., Рогожин С. В., Цюрупа М. П. Новый подход к созданию равномерно сшитых макросетчатых полистирольных структур // Высокомол. соединения. 1973. Т. 15Б. № 6. С. 463.

3. Tsyurupa M.P., Ilyin M. M., Andreeva A. I., Davankov V. A. Use of the hypercrosslinked polystyrene sorbents "Styrosorb" for solid phase extraction of phenols from water // Fresenius J. Anal. Chem. 1995. V. 352. № 7-8. P. 672.

4. Tsyurupa M.P., Maslova LA., Andreeva A. I., Mrachkovskaya T. A., Davankov V. A. Sorption of organic compounds from aqueous media by hypercrosslinked polystyrene sorbents "Styrosorb" // React. Polym 1995. V. 25. Р. 69

5. Хрящевский А. В., Нестеренко П.Н., Тихомирова Т.И., Фадеева В.И., Шпигун О.А. Патроны с макропористыми полимерными сорбентами для концентрирования первичных алифатических аминов при их определении методом высокоэффективной жидкостной хроматографии // Журн. аналит. химии. 1997. Т. 52. № 5. С. 485.

6. Хрящевский А. В. Сорбционное концентрирование первичных длинноцепочечных алифатических аминов и фенолов и их определение методом обращенно-фазовой высокоэффективной жидкостной хроматографии. Дисс. ... канд. хим. наук. М.: МГУ, 1997.

7. Тихомирова Т.И., Хрящевский А. В. Фадеева В.И., Нестеренко П.Н., Шпигун О. А. Сорбция алифатических аминов макропористым полимерным сорбентом и кремнеземом, химически модифицированным гексадецильными группами // Вестн. Моск. ун-та. Сер. 2. Химия. 1999. Т. 40. № 6. С. 365.

8. Пеннер Н. А., Нестеренко П. Н., Рыбалко М. А. Применение сверхсшитого полистирола для определения пирокатехина, резорцина и гидрохинона методом ОФ ВЭЖХ с предварительным динамическим концентрированием на потоке // Журн. аналит. химии. 2001. T. 56. № 10. С. 1067
9. Медведева О.М., Куракина В.С., Дмитриенко С. Г., Шпигун О.А. Разделение и определение фенолкарбоновых кислот методом капиллярного зонного электрофореза с предварительным концентрированием на сверхсшитом полистироле // Журн. аналит. химии. 2004. Т. 59. № 7. С. 752.

10. Дмитриенко С.Г., Тихомирова Т.И., Апяри В.В., Толмачева В.В., Кочук Е. В., Золотов Ю.А. Применение сверхсшитых полистиролов для концентрирования и разделения органических соединений и ионов элементов // Журн. аналит. химии. 2018. Т. 73. № 11. С. 830-842.

11. Tsyurupa M.P., Davankov V.A. Porous structure of hypercrosslinked polystyrene: state-of-the-art mini-review // React. Funct. Polym. 2006. V. 66. P. 768

12. Davankov V.A., Tsyurupa M.P. Hypercrosslinked polymeric networks and adsorbing materials, Amsterdam: Elsevier, 2011. 648 pp. (in series Comprehensive Analytical Chemistry. V. 56).

13. Удалова А. Ю. Сорбционное концентрирование антибиотиков тетрациклиновой группы для их последующего определения. Дисс. ... канд. хим. наук, Москва, МГУ, 2015.

14. Удалова А. Ю., Дмитриенко С. Г., Натчук С. В., Апяри В.В., Золотов Ю.А. Концентрирование антибиотиков тетрациклиновой группы на сверхсшитом полистироле и их определение в водах методом высокоэффективной жидкостной хроматографии // Журн. аналит. химии. 2015. Т. 70. № 3. С. 273.

15. Удалова А. Ю., Дмитриенко С. Г., Апяри В.В.Сорбция антибиотиков тетрациклиновой группы на сверхсшитом полистироле из водных и водно-органических сред // Журн. физ. химии. 2015. Т. 89. № 6. С. 1025

16. Zhou Q., Li Z., Shuang C., Li A., Zhang M., Wang M. Efficient removal of tetracycline by reusable magnetic microspheres with a high surface area // Chem. Eng. J. 2012. V. 210. P. 350.

17. Zhang M., Li A., Zhou Q., Shuang C., Zhou W., Wang M. Effect of pore size distribution on tetracycline adsorption using magnetic hypercrosslinked resins // Microporous Mesoporous Mater. 2014. V. 184. P. 105. 
18. Кудринская В.А. Сорбционное концентрирование кверцетина и других флавоноидов и их определение различными методами. Дисс. ... канд. хим. наук, Москва, МГУ, 2010.

19. Дмитриенко С. Г., Степанова А. В., Кудринская В. А., Апяри В. В. Особенности разделения флавоноидов методом обращенно-фазовой высокоэффективной хроматографии на колонке Luna 5u C18(2) // Вестн. Моск. Ун-та. Сер. 2. Химия. 2012. Т. 53. № 6. 369-373.

20. Кочук Е. В. Определение сульфаниламидов методами вэжх и спектрофотометрии после сорбционного концентрирования. Дисс. ... канд. хим. наук, Москва, Мгу, 2013.

21. Dmitrienko S. G., Kochuk E. V., Tolmacheva V. V., Apyari V.V., Zolotov Yu.A. Determination of the total content of some sulfonamides in milk using solid-phase extraction coupled with offline derivatization and spectrophotometric detection // Food Chem. 2015. V. 188. Р. 51.

22. Дмитриенко С. Г., Кочук Е. В., Толмачева В. В., Апяри В. В., Золотов Ю.А. Сравнение сорбентов для концентрирования сульфаниламидов из водных растворов перед их определением методом ВЭЖХ // Журн. аналит. химии. 2013. Т. 68. № 10. С. 966.

23. Кочук Е. В., Дмитриенко С. Г. Сорбция сульфаниламидов на сверхсшитом полистироле // Журн. физ. химии. 2011. Т. 85. № 1. С. 95.

24. Рамазанова Г.Р. Сорбционно-спектроскопическое определение синтетических анионных пищевых красителей. Дисс. ... канд. хим. наук, Москва, МГУ, 2016.

25. Tikhomirova T. I., Ramazanova G.R., Apyari V.V. Effect of nature and structure of synthetic anionic food dyes on their sorption onto different sorbents: Peculiarities and prospects // Microchem. J. 2018 V. 143. P. 305

26. Tolmacheva V. V., Yarykin D. I., Serdiuk O. N., Apyari V. V., Dmitrienko S. G., Zolotov Yu. A. Adsorption of catecholamines from their aqueous solutions on hypercrosslinked polystyrene // React. Funct. Polym. 2018. V. 131. P. 56-63.

27. Медведева О.М. Определение фенолкарбоновых кислот методом капиллярного зонного электрофореза и спектроскопии диффузного отражения после сорбционного концентрирования. Дисс. ... канд. хим. наук, Москва, Мгу, 2004

28. Loos R., Barcelo D. Determination of haloacetic acids in aqueous environments by solid-phase extraction followed by ion-pair liquid chromatography- electrospray ionization mass spectrometric detection // J. Chromatogr. A. 2001. V. 938. P. 45.

29. Андреева Е. Ю. Сорбционное выделение и концентрирование метилксантинов и их определение различными методами. Дисс ... канд. хим. наук, Москва, МГУ, 2011.

30. Дмитриенко С. Г., Андреева Е. Ю., Толмачева В. В., Золотов Ю. А Концентрирование метилксантинов на сверхсшитом полистироле и их последующее определение методом высокоэффективной жидкостной хроматографии // Журн. аналит. химии. 2013. Т. 68 № 2. С. 108 .

31. Андреева Е. Ю., Дмитриенко С. Г., Золотов Ю. А. Сорбция кофеина и теофиллина на сверхсшитом полистироле // Вестн. Моск. ун-та Сер. 2. Химия. 2010. Т. 51. № 1. С. 48

32. Цюрупа М.П., Блинникова 3. К., Проскурина Н. А., Пастухов А. В. Павлова Л. А., Даванков В.А. Сверхсшитый полистирол-первый нанопористый полимерный материал // Российские нанотехнологии. 2009. Т. 4. С. 109-117.

33. Penner N. A., Nesterenko P. N. Anion-exchange ability of neutral hydrophobic hypercrosslinked polystyrene // Anal. Commun. 1999. V. 36. Р. 199-201.

34. Хрящевский А. В., Подловченко М. Б., Нестеренко П. Н., Шпигун О.А. Применение сверхсшитого макросетчатого полистирола для концентрирования фенолов // Вестн. Моск. ун-та. Сер. 2. Химия. 1998. Т. 39. № 3. С. 196.

35. Дмитриенко С. Г., Андреева Е. Ю., Толмачева В. В., Терентьева Е.А. Особенности сорбции метилксантинов сорбентами различной природы // Журн. физ. химии. 2013. Т. 87. № 5. С. 874.

36. Tolmacheva V. V., Apyari V.V., Furletov A. A., Dmitrienko S. G., Zolotov Yu. A. Facile synthesis of magnetic hypercrosslinked polystyrene and its application in the magnetic solid-phase extraction of sulfonamides from water and milk samples before their HPLC determination // Talanta. 2016. V. 152. P. 203-210.
37. Wang W., Ma Y., Zhou Q., Shuang C., Zhang M., Li A. Preparation of a permanent magnetic hypercrosslinked resin and assessment of its ability to remove organic micropollutants from drinking water // Front. Environ. Sci. Eng. 2015. V. 9. P. 96-104

38. Castaldo R., Gentile G., Avella M., Carfagna C., Ambrogi V. Microporous hyper-crosslinked polystyrenes and nanocomposites with high adsorption properties: a review // Polym. 2017. V. 9. 651. DOI:10.3390/polym9120651

39. Филиппов О. А., Посох В. В., Тихомирова Т. И., Шаповалова Е.Н., цизин Г.И., Шпигун О.А., Золотов Ю.А. Проточное сорбционнохроматографическое определение фенолов с амперометрическим детектированием // Журн. аналит. химии. 2002. Т. 57. № 9. С. 933.

40. Филиппов О. А., Тихомирова Т.И., Шаповалова Е. Н., Цизин Г.И., Шпигун О.А., Золотов Ю.А. Проточное сорбционное концентрирование и ОФ ВЭЖХ определение фенолов // Журн. аналит. химии. 2003. T. 58. № 7. C. 703.

41. Puig D., Barcelo D. Comparison of different sorbent materials for on-line liquid-solid extraction followed by liquid chromatographic determination of priority phenolic compounds in environmental waters // J. Chromatogr. A. 1996. V. 733. Р. 371-381.

42. Паутова А. К., Ревельский А. И. Сорбционное концентрирование фенилкарбоновых кислот (биомаркеров сепсиса) из модельных растворов на сверхсшитом полистироле // Физикохимия поверхности и защита материалов. 2014. Т. 50. № 6. С. 640.

43. Bylda C., Velichkova V., Bolle J., Thiele R., Kobolda U., Volmer D. Magnetic beads as an extraction medium for simultaneous quantification of acetaminophen and structurally related compounds in human serum // Drug Test. Analysis 2015. V. 7. P. 457.

44. Толмачева В. В., Апяри В. В., Ярыкин Д. И., Дмитриенко С. Г. Спектрофотометрическое определение суммарного содержания сульфаниламидов в молоке после их сорбционного выделения с помощью магнитного сверхсшитого полистирола // Журн. аналит. химии. 2016. T. 71. № 8. C. 867.

45. Salek P., Korecka L., Horak D., Petrovsky E., Kovarova J., Metelka R., Cadkova M., Bılkova Z. Immunomagnetic sulfonated hypercrosslinked polystyrene microspheres for electrochemical detection of proteins // J. Mater. Chem. 2011. V. 21. P. 14783.

\section{REFERENCES}

1. Davankov V. A., Rogozhin S. V., Tsyurupa M. P. Patent № 299165 USSR, 1969.

2. Davankov V.A., Rogozhin S.V., Tsyurupa M.P. A New Approach to the Creation of Uniformly Cross-Linked Macronet Polystyrene Structures. Vysokomolekulyarnye soedineniya - High Molecular Weight Compounds, 1973, V. 15B, № 6, p. 463.

3. Tsyurupa M.P., Ilyin M. M., Andreeva A.I., Davankov V. A. Use of the hypercrosslinked polystyrene sorbents "Styrosorb" for solid phase extraction of phenols from water // Fresenius J. Anal. Chem. 1995. V. 352. № 7-8. P. 672.

4. Tsyurupa M.P., Maslova LA., Andreeva A. I., Mrachkovskaya T. A., Davankov V.A. Sorption of organic compounds from aqueous media by hypercrosslinked polystyrene sorbents "Styrosorb" // React. Polym. 1995. V. 25. P. 69.

5. Khryashchevskii A. V., Nesterenko P. N., Tikhomirova T.I., Fadeeva V.I., Shpigun O.A. Cartridges packed with macroporous polymer sorbents for preconcentrating primary aliphatic amines and their determination by high-performance liquid chromatography // J. Anal. Chem. 1997. V. 52. № 5. P. 429.

6. Khryashchevskii A. V. Sorption preconcentration of primary long-chain aliphatic amines and phenols and their determination by the method of reversed-phase high-performance liquid chromatography. PhD thesis. Moscow, Lomonosov Moscow State University, 1997.

7. Tikhomirova T.I., Khryashchevskii A. V., Fadeeva V.I., Nesterenko P. N., Shpigun O. A. Sorption of aliphatic amines with macroporous polymeric sorbent and silica as chemically modified by hexadecyl moieties // Moscow Univ. Chem. Bull. 1999. V. 40. № 6. P. 365.

8. Penner N. A., Nesterenko P. N., Rybalko M. A. Use of Hypercrosslinked Polystyrene for the Determination of Pyrocatechol, Resorcinol, and 
Hydroquinone by Reversed-Phase HPLC with Dynamic On-line Preconcentration // J. Anal. Chem. 2001. V. 56. № 10. P. 934.

9. Medvedeva O. M., Kurakina V.S., Dmitrienko S. G., Tikhomirova T. I., Shpigun O.A. Separation and determination of phenolcarboxylic acids by capillary zone electrophoresis with dynamic preconcentration on hypercrosslinked polystyrene // J. Anal. Chem. 2004. V. 59. № 7. P. 669.

10. Dmitrienko S. G., Tikhomirova T. I., Apyari V.V., Tolmacheva V.V., Kochuk E. V., Zolotov Yu. A. Application of Hypercrosslinked Polystyrenes to the Preconcentration and Separation of Organic Compounds and Ions of Elements // J. Anal. Chem. 2018. V. 73. № 11. P. 1053.

11. Tsyurupa M.P., Davankov V.A. Porous structure of hypercrosslinked polystyrene: state-of-the-art mini-review // React. Funct. Polym. 2006 V. 66. P. 768

12. Davankov V. A., Tsyurupa M.P. Hypercrosslinked polymeric networks and adsorbing materials, Amsterdam: Elsevier, 2011. 648 pp. (in series Comprehensive Analytical Chemistry. V. 56)

13. Udalova A. Yu. Sorption Preconcentration of Antibiotics of the Tetracycline Group for their Subsequent Determination. PhD thesis. Moscow, Lomonosov Moscow State University, 2015.

14. Udalova A. Yu., Dmitrienko S.G., Natchuk S. V., Apyari V.V., Zolotov Yu.A Preconcentration of Tetracycline Antibiotics on a Hyper-Crosslinked Polystyrene and Their Determination in Waters by High Performance Liquid Chromatography // J. Anal. Chem. 2015. V. 70. № 3. P. 292

15. Udalova A. Yu., Dmitrienko S. G., Apyari V. V. Sorption of Tetracycline Antibiotics on Hyper-Crosslinked Polystyrene from Aqueous and Aqueous-Organic Media // Russ. J. Phys. Chem. A. 2015. V. 89. № 6 P. 1082-1086.

16. Zhou Q., Li Z., Shuang C., Li A., Zhang M., Wang M. Efficient removal of tetracycline by reusable magnetic microspheres with a high surface area // Chem. Eng. J. 2012. V. 210. P. 350.

17. Zhang M., Li A., Zhou Q., Shuang C., Zhou W., Wang M. Effect of Pore Size Distribution on Tetracycline Adsorption using Magnetic Hypercrosslinked Resins // Microporous Mesoporous Mater. 2014. V. 184 P. 105.

18. Kudrinskaya V. A. Sorption Preconcentration of Quercetin and Other Flavonoids and Their Determination by Various Methods. PhD thesis Moscow, Lomonosov Moscow State University, 2010.

19. Dmitrienko S. G., Stepanova A. V., Kudrinskaya V.A., Apyari V.V. Specifics of Separation of Flavonoids by Reverse Phase High Performance Liquid Chromatography on the Luna $5 \mathrm{u} \mathrm{C18(2)} \mathrm{Column} \mathrm{//} \mathrm{Moscow} \mathrm{Univ.}$ Chem. Bull. 2012. V. 67. № 6. P. 254.

20. Kochuk E. V. Determination of Sulfonamides by the HPLC and Spectrophotometry Methods after Sorption Preconcentration. PhD thesis Moscow, Lomonosov Moscow State University, 2013.

21. Dmitrienko S. G., Kochuk E.V., Tolmacheva V.V., Apyari V.V. Zolotov Yu. A. Determination of the total content of some sulfonamides in milk using solid-phase extraction coupled with off-line derivatization and spectrophotometric detection // Food Chem. 2015. V. 188. P. 51.

22. Dmitrienko S. G., Kochuk E. V., Tolmacheva V. V., Apyari V. V. Zolotov Yu. A. Comparison of Adsorbents for the Preconcentration of Sulfanilamides from Aqueous Solutions Prior to HPLC Determination // J. Anal. Chem. 2013. V. 68. № 10. P. 871.

23. Kochuk E. V., Dmitrienko S. G. Sorption of Sulfanilamides on Highly CrossLinked Polystyrene // Russ. J. Phys. Chem. A. 2011. V. 85. № 1. P. 89.

24. Ramazanova G. R. Sorption-Spectroscopic Determination of Synthetic Anionic Food Dyes. PhD thesis. Moscow, Lomonosov Moscow State University, 2016

25. Tikhomirova T. I., Ramazanova G. R., Apyari V. V. Effect of nature and structure of synthetic anionic food dyes on their sorption onto different sorbents: Peculiarities and prospects // Microchem. J. 2018. V. 143. P. 305.

26. Tolmacheva V.V., Yarykin D. I., Serdiuk O. N., Apyari V. V., Dmitrienko S.G., Zolotov Yu. A. Adsorption of catecholamines from their aqueous solutions on hypercrosslinked polystyrene // React. Funct. Polym. 2018. V. 131. P. 56.

27. Medvedeva O.M. Determination of Phenol Carboxylic Acids by Capillary Zone Electrophoresis and Diffuse Reflectance Spectroscopy after Sorption Preoncentration. PhD thesis. Moscow, Lomonosov Moscow State University, 2004
28. Loos R., Barcelo D. Determination of haloacetic acids in aqueous environments by solid-phase extraction followed by ion-pair liquid chromatography - electrospray ionization mass spectrometric detection // J. Chromatogr. A. 2001. V. 938. P. 45.

29. Andreeva E. Yu. Sorption Isolation and Concentration of Methylxanthines and Their Determination by Various Methods. PhD thesis. Moscow, Lomonosov Moscow State University, 2011.

30. Dmitrienko S. G., Andreeva E. Yu., Tolmacheva V. V., Zolotov Yu. A. Preconcentration of Methylxanthines on Hyper-Cross-Linked Polystyrene Followed by their Determination by High-Performance Liquid Chromatography // J. Anal. Chem. 2013. V. 68. № 2. P. 95.

31. Andreeva E. Yu., Dmitrienko S. G., Zolotov Yu. A. Sorption of Caffeine and Theophylline on Hypercrosslinked Polystyrene // Moscow Univ. Chem. Bull. 2010. V. 65. № 1. P. 38

32. Tsyurupa M.P., Blinnikova Z. K., Proskurina N. A., Pastukhov A.V., Pavlova L. A., Davankov V. A. Hypercrosslinked polystyrene - first nano-porous polymeric material. Rossiyskiye nanotekhnologii - Russian Nanotechnologies, 2009, V. 4, pp. 109-117.

33. Penner N. A., Nesterenko P. N. Anion-exchange ability of neutral hydrophobic hypercrosslinked polystyrene // Anal. Commun. 1999. V. 36. P. 199

34. Khryashchevskii A. V., Podlovchenko M. B., Nesterenko P. N., Shpigun O. A. Use of hypercrosslinked macroreticular polystyrene for the phenols preconcentration // Moscow Univ. Chem. Bull. 1998. V. 39. № 3. P. 196.

35. Dmitrienko S. G., Andreeva E. Yu., Tolmacheva V. V., Terentieva E. A. Sorption of Methylxanthines by Different Sorbents // Russ. J. Phys. Chem. A. 2013. V. 87. № 5. P. 856.

36. Tolmacheva V.V., Apyari V.V., Furletov A. A., Dmitrienko S.G., Zolotov Yu. A. Facile synthesis of magnetic hypercrosslinked polystyrene and its application in the magnetic solid-phase extraction of sulfonamides from water and milk samples before their HPLC determination // Talanta. 2016. V. 152. P. 203.

37. Wang W., Ma Y., Zhou Q., Shuang C., Zhang M., Li A. Preparation of a permanent magnetic hypercrosslinked resin and assessment of its ability to remove organic micropollutants from drinking water // Front. Environ. Sci. Eng. 2015. V. 9. P. 96

38. Castaldo R., Gentile G., Avella M., Carfagna C., Ambrogi V. Microporous hyper-crosslinked polystyrenes and nanocomposites with high adsorption properties: a review // Polym. 2017. V. 9. 651. DOI:10.3390/ polym9120651

39. Filippov O. A., Posokh V.V., Tikhomirova T.I., Shapovalova E. N., Tsizin G.I., Shpigun O.A., Zolotov Yu.A. On-line sorptionchromatographic determination of phenols with amperometric detection // J. Anal. Chem. 2002. V. 57. № 9. P. 788.

40. Filippov O. A., Tikhomirova T. I., Shapovalova E. N., Tsizin G.I., Shpigun O. A., Zolotov Yu. A. Flow Sorption Preconcentration in the Determination of Phenols by Reversed-Phase High-Performance Liquid Chromatography // J. Anal. Chem. 2003. V. 58. № 7. P. 625.

41. Puig D., Barcelo D. Comparison of different sorbent materials for on-line liquid-solid extraction followed by liquid chromatographic determination of priority phenolic compounds in environmental waters // J. Chromatogr. A. 1996. V. 733. P. 371.

42. Pautova A. K., Revelsky A. I. Sorption Concentration of Phenylcarboxylic Acids (Biomarkers of Sepsis) from Standard Test Solutionson HyperCrossLinked Polystyrene // Prot. Met. Phys. Chem. 2014 V. 50. № 6. P. 768.

43. Bylda C., Velichkova V., Bolle J., Thiele R., Kobolda U., Volmer D. Magnetic beads as an extraction medium for simultaneous quantification of acetaminophen and structurally related compounds in human serum // Drug Test. Analysis 2015. V. 7. P. 457.

44. Tolmacheva V. V., Apyari V. V., Yarykin D. I., Dmitrienko S. G. Spectrophotometric Determination of the Total Concentration of Sulfonamides in Milk after Adsorption Separation Using Magnetic Hypercrosslinked Polystyrene // J. Anal. Chem. 2016. V. 71. № 8. P. 834

45. Salek P., Korecka L., Horak D., Petrovsky E., Kovarova J., Metelka R., Cadkova M., Bılkova Z. Immunomagnetic sulfonated hypercrosslinked polystyrene microspheres for electrochemical detection of proteins // J. Mater. Chem. 2011. V. 21. P. 14783. 